\title{
A LÍNGUA PORTUGUESA NO MUNDO
}

\author{
THE PORTUGUESE LANGUAGE IN THE WORLD
}

\author{
NeIly CARVALHO \\ PG Letras (UFPE) \\ nellycar@terra.com.br
}

RESUMO: A Língua portuguesa é a sétima em número de falantes no mundo, consequência das grandes navegações, empreendidas pelos lusos, colonizando terras na Ásia, África e América. Difundiu-se por um vasto domínio que alcançou as regiões mais afastadas, enriquecendo-se com um caudal de experiências: flora estranha, fauna surpreendente e condições religiosas, políticas e sociais diferentes. Com isso, tornou-se uma língua de cultura básica no mundo moderno, tendo, ao lado disso, uma literatura rica e vasta .A partir de 1500, iniciou-se a saga brasileira, construindo-se pouco a pouco a maior nação falante de língua portuguesa do mundo. Além da herança recebida, vieram ampliar a língua portuguesa no Brasil, as contribuições indígenas e africanas, diferenciando o falar do Brasil do falar herdado de Portugal. Com as várias imigrações havidas no decorrer dos séculos de formação do país, foram desenvolvidas nas diversas regiões, dialetos diferentes entre si, mas sempre intercompreensíveis .Além do mais, a clivagem social no país determinou diferenças entre os falares das diversas classes Mas, a língua portuguesa, respeitada e reconhecida sua pluralidade de formas ( vocabulário, fonética, sintaxe) continua sendo compreendida, em todo o território nacional, como a língua vernácula. Na transplantação da língua não foi apenas a língua comum que atravessou oceanos, mas todo um domínio linguístico. A língua portuguesa entrou em contato com tantas coisas novas para denominar, tantas sensações para referir, tantas estranhezas para contar, que teve de munir-se de um vocabulário renovado, tomado das línguas em contato. O núcleo inicial manteve-se o que lhe conferiu o caráter un Nenhuma língua viva é um todo uniforme. Assim acontece também com o português, ainda mais uma língua transplantada. Ela evoluiu à margem do academicismo e do cerceamento das gramáticas prescritivas. Mas esta língua transplantada desenvolveu-se uniformemente dentro de tendências preexistente.

Palavras-chave: Língua portuguesa; pluralidade de formas; contribuições; diversidade; língua transplantada.

ABSTRACT: The Portuguese Language is the seventh regarding speakers' number in the world, a consequence of the great navigations, carried out by the Portuguese, colonizing lands in Asia, Africa and America. It spread through a vast domain, which reached the farthest regions, enriching itself with a great flow of experiences: foreign flora, surprisingly fauna and different religious, political and social conditions. Thus, it became a language of basic culture in the modern world, having, alongside, a rich and great literature. From 1500, there started the Brazilian saga, building, little by little, the biggest spoken nation of Portuguese Language in the world. Besides the heritage received, the Portuguese Language in Brazil was enlarged by indigenous and African contributions, making the spoken language in Brazil different from the spoken language inherited from Portugal. Along with the various immigrations throughout the centuries while the country was rising, it was developed, in several regions, different dialects among themselves, but always inter-understood. Moreover, social rupturing has 
determined differences among speakers of diverse classes. Nevertheless, the Portuguese language, with its respected and known plurality of forms (vocabulary, phonetics, syntax) remains being understood, all through the national territory, as the vernacular language. In the transplantation of the language, it was not only the ordinary language, which crossed oceans, but a whole linguistic domain. The Portuguese language got into contact with such many new things to denominate, such many sensations to refer to, and such many strangeness to tell that it had to provide itself with a renewed vocabulary, borrowed from the languages in touch. The initial nucleus was kept, which conferred its character. No living language is uniform in its whole. And the same thing happens to the Portuguese, yet, a transplanted language. It has evolved aside the academicism and restriction of prescriptive grammars. Furthermore, this transplanted language has developed uniformly within preexistent trends.

Key words: Portuguese language; plurality of forms; contributions; diversity; transplantation of language.

\section{Introdução}

A língua portuguesa, falada por cerca de 200 milhões de pessoas, coloca-se, do ponto de vista quantitativo, como a sexta língua do mundo, precedida pelo chinês, inglês, russo, espanhol, árabe e bengali. Aproximadamente a sétima parte da terra se expressa em português. Essa quantificação de números de falantes não é aceita por unanimidade. Alguns autores, como Arnaldo Niskier, consideram-na a quinta e outros, a oitava. Mas, a verdade é que a língua portuguesa está entre as dez línguas mais faladas, num universo de cerca de 10.000 .

A sua expansão foi consequência da grande epopéia dos Descobrimentos em que a Península Ibérica ampliou para a Europa e para a civilização ocidental os limites da terra conhecida. A língua portuguesa, junto com o espanhol, difundiu-se por um vasto domínio que alcançou as regiões mais afastadas, enriquecendo-se com um caudal de experiências: flora estranha, fauna surpreendente e condições religiosas, políticas e sociais diferentes das conhecidas até então. Acolheu no seu vocabulário uma quantidade imensa de termos, enquanto cedia aos nativos a possibilidade de comunicação ampla que lhe dava a língua européia, junto com a técnica da escrita e a já existente tradição literária.

Porém, vai muito além disso, pois vem a ser uma das línguas de cultura mais representativa do mundo ocidental, tendo, na sua literatura, um acervo de obras-primas que fazem parte do patrimônio universal. Está em pé de igualdade com o francês, o inglês, o alemão, o espanhol e o italiano, além do exótico e distanciado idioma de Tolstoi, o russo. E, com essas línguas, forma-se a cultura básica do homem moderno. 
Diz Jacinto Prado Coelho (1977, p. 25), estudioso português:

O português é uma língua forjada e trabalhada durante mais de um milênio por sucessivas experiências coletivas, desenvolvidas a partir dos Descobrimentos, em todos os continentes, uma língua que está a ser constantemente enriquecida pela produção de várias literaturas originais, umas de âmbito nacional, outras de cunho regional - parte integrante da cultura universal, o que legitima, ou melhor, impõe os nossos valores perante o conjunto das nações do globo.

\section{Domínio Geográfico da Língua Portuguesa}

Com a conquista de Ceuta, porta da África, iniciou-se a expansão do português como língua de colonização e conquista. A seguir, foram colonizadas as ilhas atlânticas de Madeiras e Açores (desabitadas) e, em sucessivas conquistas, toda a costa ocidental da África. Seguiu-se o feito inédito, em 1488, de dobrar do cabo das Tormentas, que abriu os horizontes para os conquistadores e para seu instrumento de comunicação, a língua.

Os portos da Índia, Abissínia, Arábia e até os do Japão e da China foram rota dos portugueses que, nos contatos, realizaram as trocas linguísticas: deixaram termos novos para as línguas locais e introduziram novidades em sua própria língua, referentes aos fatos vividos, objetos e hábitos encontrados, tornando-se a língua portuguesa o canal da inovação vocabular na Europa, o vetor das novidades dos novos mundos, para as demais culturas européias.

A partir de 1500, na imensidade do continente sul-americano, iniciou-se a saga brasileira, construindo-se pouco a pouco a maior nação falante de língua portuguesa do mundo.

No Oriente, como já foi citado, durante todo o século XVI, o comércio marítimo divulgou o idioma português, tornando-o a língua da comunicação entre europeus e orientais, advindo destes contatos a formação de duas línguas francas: o indo-português e o malaio-português. Atestado da presença do português na Ásia são os vocábulos lusos ainda hoje infiltrados nas diversas línguas orientais.

Ainda na América do Sul, foi o português a base do dialeto que constitui a língua crioula de Curaçao. No Pacífico, na ilha de Java, persistem ainda hoje dialetos crioulos do português. Em Malaca (Malásia) e Singapura, permanecem entre camponeses idosos, os antigos dialetos do português crioulo.

Para Pilar Vasquez Cuesta, a geografia do Português é traçada, inserindo-se o 
idioma no mapeamento da área linguística galaico-portuguesa, com quatro tipos de linguagem literária, o português europeu, o português brasileiro, o galego e o crioulo cabo-verdiano, correspondendo às normas cultas com igual denominação, assim como aos mesmos tipos de linguagem popular. Ao lado da norma-padrão, a autora cita as variedades dialetais na Europa, África e Brasil e dialetos crioulos, quais sejam o caboverdiano, o da Guiné, o de São Tomé, Príncipe e Ano Bom, o de Macau, o malaioportuguês e o de Timor.

No Brasil, quanto à sua situação de colônia portuguesa, é obrigatório lembrar os estudos clássicos de Gilberto Freyre e de Sérgio Buarque de Holanda.

Diz o autor já citado que o primeiro dedicou-se a construir uma antropologia existencial do Nordeste açucareiro em livros notáveis, como Casa-grande \& Senzala e Sobrados e Mocambos. O segundo descreveu com minúcia e elegância os hábitos do sertanejo luso-tupi em análises pioneiras de nossa cultura material (Caminhos $e$ fronteiras) depois de ter empreendido uma síntese do processo colonizador em Raízes do Brasil.

\begin{abstract}
"No trato dos comportamentos familiares, os ensaios de Gilberto Freyre e de Sérgio Buarque sugerem uma interpretação psicocultural do passado brasileiro. Torna-se uma leitura da nossa história escorada na hipótese geral de que o conquistador português já trazia em si traços de caráter recorrentes, que Sérgio Buarque chama de determinantes psicológicas, tais como o individualismo, qualificado como exaltação extrema da personalidade, o espírito aventureiro (daí, a ética da aventura oposta à ética do trabalho), o natural inquieto e desordenado, a cordialidade, o sentimentalismo sensual, que se exerce sem peias no que Gilberto Freyre classifica de patriarcalismo polígamo, a plasticidade social, a versatilidade, a tendência à mestiçagem (que já viria dos cruzamentos com os mouros) intensificada pela carência de orgulho racial, atributo que comparece nas caracterizações de ambos os estudiosos.” (Bosi-1994)
\end{abstract}

Foram estes os vários modos da chamada assimilação luso-africana e luso-tupi que marcaram a história da colonização tanto no Nordeste dos engenhos e quilombos quanto no Sul das bandeiras e missões. A cultura resultante está impressa na língua, nas variedades eruditas e literárias, mas sobretudo nas populares, e dela derivou uma literatura com estilo próprio e personalidade brilhante, segundo Pilar Vasquez Cuesta.

\title{
2. Consequências da Colonização: uma língua transplantada
}

Nenhuma língua viva é um todo uniforme. Assim acontece também com o português, ainda mais uma língua transplantada. Ela evoluiu à margem do 
academicismo e do cerceamento das gramáticas prescritivas.

Vendriés, linguista francês, lembra que o esforço dos gramáticos em manter a língua estática, sem mudanças, funciona como a superfície congelada de um rio. Por baixo do gelo, o curso d'água - a vida continua a correr e mais adiante com força, rebenta a camada que o imobiliza. A atividade linguística torna o sistema dinâmico, não permite “congelamento"; nem sons, nem formas, nem sentidos são imutáveis. As mudanças se fazem lentas, imperceptíveis, porém inexoráveis. Essas mudanças são consequências da própria história dos povos no tempo, no espaço, nas condições sociais, de que resultam as variantes.

O povo português, na sua permanente inquietação e sede de expansão, assimilou influências de falares e de nomes de coisas e costumes que descobriu por esses mundos que desbravou, conforme já foi referido.

Mas a língua transplantanda desenvolveu-se uniformemente dentro de tendências preexistente. Em relação ao Brasil, deve-se observar como bem o faz Serafim da Silva Neto, que, embora a colonização tenha se iniciado no século XVI, só no século XVII é que a maior parte do território. Nesses núcleos a linguagem implantada foi a das províncias, sobretudo do norte de Portugal, e a dos Açores, no Rio Grande do Sul (com Porto dos Casais) e Santa Catarina, mas também no Pará, no extremo Norte do Brasil. Atribui-se aos paraenses como característica, num tom jocoso, a frase "uma canua cheia de cucos de pupa a prua", ou seja, a passagem do o tônico a u, explicando-se como causa a influência dos falares açorianos, dos povoadores iniciais.

$\mathrm{Na}$ transplantação da língua não foi apenas a língua comum que atravessou oceanos, mas todo um domínio linguístico. A língua portuguesa entrou em contato no mundo da Aventura Lusa com tantas coisas novas para denominar, tantas sensações para referir, tantas estranhezas para contar, que teve de munir-se de um vocabulário renovado, tomado das línguas em contato. O núcleo inicial manteve-se o que lhe conferiu o caráter uniforme. Os campos semânticos fundamentais permaneceram (parentesco, acidentes geográficos, partes do corpo, condições climáticas, divisão do tempo), e a estrutura da língua conservou-se: conjugação verbal, formas pronominais, palavras instrumentais, ordem frasal. O que sofreu variações foram as escolhas e usos, mas sobretudo o vocabulário referente a características regionais. A entonação constituiu-se a diversidade mais marcante. 
A unidade da língua foi mantida não numa monótona e impossível uniformidade, o que estaria fora das características de uma língua viva, mas numa unidade de admirável intercompreensão dentro de uma imensa gama de variedades. Entre as variedades brasileiras, ainda estão vivas e produtivas as de ascendência açoriana. Em pesquisas realizadas em Santa Catarina e no Rio Grande do Sul, foram recolhidos os termos guecha (vaca que ainda não deu leite) acavê e recavem (partes do carro de boi) e chimarrita (dança açoriana transplantada). A tendência nordestina de transformar o $\mathbf{g}$ em $\mathbf{x}$, explica-se pela colonização feita por imigrantes do Norte, da região do Douro e do Minho, essa por sua vez com forte influência galega.Só assim podem ser explicadas transformações, entre outras, como oxente (ó gentes) e Vixe (Virgem) usadas como interjeição e muitas outras.

Assim é a língua portuguesa, no Brasil e no resto do mundo, revelado por Portugal: uma língua em permanente mudança e expansão para adaptar-se aos tempos presentes, sem perder a ligação com suas origens. Poderíamos dizer: mudam-se os tempos, muda-se a linguagem, parafraseando Camões, mas não a língua, que permanece como traço de unidade entre os povos.

A língua portuguesa, uma língua muito viva, é, por isso mesmo, heterogênea e ativa, testemunhando os grupos e nações que falam tão diversos entre si. Esta diversidade não afeta a unidade da língua, mas, ao contrário, enriquece-a. Se, com a diferença começa a existência, com a diversidade de usos é que ela se mantém. Só uma língua sem vida e sem uso (o latim, por exemplo) é que se mantém uniforme. Paul Teyssier chama a atenção para o caráter ecumênico da língua portuguesa, lembrando que é fundamental a unidade Portugal-Brasil, não devendo ser atingido um limite para além do qual se torne impossível à comunicação.

Entraram no século XXI, como falantes oficiais da Língua Portuguesa, as seguintes nações:

na Europa: Portugal;

na América do Sul, o Brasil;

na África, a República de Angola; São Tomé e Príncipe; Cabo Verde; Moçambique; Guiné-Bissau;

na Ásia, Timor Leste.

Macau, antiga possessão portuguesa, foi devolvida à China em 1999 e Goa 
(Índia), há muito deixou de ser falante oficial do português. Em compensação, Timor Leste só em 2001, com sua independência, passou a integrar a comunidade de países lusófonos, adotando o português como língua oficial.

\section{Mapeamento político das línguas mais faladas}

Analisando a situação atual da língua portuguesa em relação aos países lusófonos, pode-se observar que ela não é uniforme, pois, apesar de oficial, o português não é língua materna de todos os cidadãos dos países africanos e, no Brasil, da população indígena.

Para estudar esse fator, observa-se que a irradiação mundial de uma língua desenvolve-se em três planos diversos. O primeiro é a função de língua materna. $\mathrm{O}$ segundo é o de língua oficial de um Estado. O terceiro é o de língua de comunicação mundial. Uma rápida vista pelas estatísticas mais recentes mostra que a ordenação das línguas pela sua expansão no mundo seria a seguinte, como línguas oficiais:

O chinês - mandarim;

o inglês;

o urdu;

o espanhol;

o russo;

o português;

o malaio;

o árabe;

o bengali;

o japonês em igualdade de condições com o francês, o alemão ;

o italiano.( Fonte: jornal O Público. Lisboa10/07/99)

A análise é mais fina ao distinguir o papel materno do oficial. Começando pelo fim, o alemão é materno para cerca de 105 milhões de pessoas, mas oficial para 95 milhões apenas. Em comparação, o francês é materno só para 75 milhões, mas é oficial para 135. Isto pelo fato de as antigas colônias africanas da França o terem por língua de estado e o fato de a Alemanha não ter colônias há mais de 90 anos, havendo, porém, cidadãos de fala alemã em países europeus de outras línguas oficiais. No caso do português e do malaio, muito próximos em número de falantes, a língua portuguesa é 
materna para 175 milhões e oficial para 195, pela mesma razão do francês; o malaio é materno para 60 milhões, mas oficial para 190.

A relação do mandarim para o inglês é como a do português para o malaio: os usuários do mandarim são em maior número, mas a proporção materno /oficial é muito maior: $75 \%$ contra $50 \%$, a favor do inglês.

Mais difícil é a quantificação do terceiro papel, o da comunicação mundial. Podem calcular-se números e tiragens de traduções, por exemplo; também o uso como língua na ONU, em congressos, nos mídias da ciência; ou as audiências de canais televisivos via satélite. Mas, fica de fora o mais difícil de medir: o número de usuários nas relações comerciais e no turismo; de leitores de belas-letras; de seguidores da mídia eletrônica e impressa; de fãs de canções e dos “clips”. Em tudo isto, uma língua irradia fora da sua área materna ou oficial.

Tentativa recente de ponderar o peso relativo das grandes línguas no mundo tarefa cheia de ciladas (escolher critérios quantificáveis e significativos, escolher a ponderação entre eles, conseguir medir o que pedem) - vem das pesquisas das universidades. A qualidade das várias pesquisas não esconde a geratriz geopolítica que as estrutura: trata-se de apurar a língua matriz da globalização em confronto com as outras línguas maiores.

\section{Conhecimento: fonte e registro}

No mundo atual, o progresso tecnológico é de tal ordem, que, através dos meios de comunicação, o mundo se tornou a famosa aldeia global. Esses meios de comunicação favorecem privilégios nos quais o fator político se associa ao econômico. Eles são transnacionais: a comunicação necessita de uma língua que também o seja, pelo valor de uma tradição cultural e, como não podia deixar de ser, pela capacidade dos povos, que a falam. As línguas que se impõem hoje formam grandes conjuntos, como a anglofonia, a francofonia, a hispanofonia, entre as quais se deve incluir a lusofonia; já não importa a identidade nacional, mas a linguística, esta transnacional. Só as línguas de sólida e extensa cultura terão condições de se impor.

O desenvolvimento socioeconômico dos países de língua latina, entre os quais se situam os países lusófonos, depende em grande parte do desenvolvimento da ciência e da tecnologia de ponta. Enquanto houver apenas, em sua maior parte, importação de 
produtos e artefatos, atendendo a interesses externos e não forem intensificadas pesquisas para conhecer processos e caminhos, atendendo a interesses internos, a ciência caminhará lentamente dentro das fronteiras dos países lusófonos. Observa-se que barreiras intra e interlinguísticas reduzem significativamente o intercâmbio informacional necessário à transferência crítica de terminologias, passando pelo crivo das reais necessidades de cada país e dificultam a formação de cientistas, técnicos e profissionais que dominem as tecnologias de ponta.

A produção do conhecimento científico deve ser incentivada dentro das fronteiras da lusofonia. Segundo as reflexões do professor Antônio Houaiss no Seminário de Tropicologia da FUNDAJ (1986), este conhecimento tem sua base no vocabulário da língua e "uma língua de cultura moderna de ponta deverá ter um vocabulário amplo, em torno de 450 mil palavras, em permanente expansão. Nas armazenagens que se fazem nas Línguas de cultura para a CEE, a fim de que a tradução seja eficaz nas diversas ciências (exatas, humanas, biológicas) e nas relações humanas, os computadores averbam pelo menos 1 milhão de conceitos para cada uma das línguas inscritas.” Continua o sábio filólogo afirmando que

o mundo da emoção, o mundo da contemplação, o mundo do afeto pode ser transmitido com poucas palavras. Mas a física, a matemática, a biologia, a filosofia necessitam de um vocabulário amplo e diversificado, ao mesmo tempo claro e exato, sem dubiedades, para que se possa construir e transmitir o conhecimento. (1986, p. 58-76)

\section{Problemas e soluções}

Segundo o linguista brasileiro Dino Preti (1994, p. 24), “a imprensa é o melhor termômetro das variações lingüísticas, da incorporação de certos usos, da sua elevação à condição de norma lingüística da comunidade.” Se for feita uma pesquisa em alguns veículos da imprensa brasileira nos últimos anos, perceber-se-á claramente que a língua portuguesa tem recebido um certo destaque. Os brasileiros estão valorizando e tratando melhor o idioma depois que o prêmio Nobel foi para o escritor português José Saramago.

Numa análise rápida, pode-se constatar que há perspectivas diferenciadas no tratamento da língua que se usa no Brasil. Há pelo menos duas visões contrastantes: a daqueles para quem a língua portuguesa está sendo massacrada e exterminada e a daqueles para quem as mudanças ocorridas na língua portuguesa falada e escrita no 
Brasil resultam de fenômenos linguísticos naturais e peculiares a qualquer língua viva. Ataliba Castilho (2009) assegura que

a questão da defesa da língua é uma falsa questão, uma vez que ninguém estaria atacando a língua portuguesa. O prestígio e a capacidade de expansão de uma língua seriam resultado não de estratégias de defesa, mas do prestígio e do poder de expansão da nação que a fala e da cultura associada a ela.

Apesar disso, alguns problemas rondam a política linguística do idioma português, como seja a falta de estabelecimento de linhas de ação e acordo entre os países lusófonos. Um deles é a dualidade ortográfica entre Brasil e Portugal (E os países africanos seguem a orientação de Portugal).

Ainda segundo Antônio Houaiss, que foi em vida o representante brasileiro nas negociações do Acordo Ortográfico, somos a única língua de cultura no mundo a ter duas ortografias oficiais. O fato traz dificuldades no plano da política editorial, das relações diplomáticas com os organismos internacionais que hesitam em relação à escolha da grafia, evidenciando-se assim a necessidade de um estatuto ortográfico que supere as peculiaridades tópicas.

Outra dificuldade é a relativa à terminologia tecnológica, tendo ligação com o tema já abordado de construção do conhecimento. Os povos lusófonos são herdeiros de uma língua e de uma visão de mundo que adaptaram e alargaram. Mas correm o risco de abastardar essa herança ao adotarem anarquicamente as denominações terminológicas que semeiam o descaso e a negligência com o próprio instrumento de comunicação. A ausência de uma política terminológica, de diretrizes únicas para adaptação e tradução de nomenclaturas técnico-científicas e sua consequência direta, o empréstimo linguístico, constitui-se, muitas vezes, uma barreira intralinguística no português. A falta de normatização (cada país, cada região, cada técnico traduz ou usa como lhe convém) contribui para confundir o jogo de cristalizações já cristalizados, a grafia e a sintaxe. Passam a ocorrer processos de derivação e flexões fora do padrões da língua. Estes são alguns dos problemas a serem superados pela lusofonia.

\section{Considerações finais}

Portugal, Brasil e África Portuguesa unem-se em torno de uma língua e de uma cultura que têm suas raízes no solo luso. A essa cultura que Silvio Elia denomina lusíada, o Brasil agregou novos elementos, assim como os países africanos, sem perder de vista a unidade. Deverá ser este fator o elemento de sustentação da língua 
portuguesa, em seus embates no mundo, pois o domínio linguístico português é o reflexo de uma outra unidade - a supranacional -, de uma substância amalgamada pela história, a que se costuma chamar de Cultura Portuguesa. Cultura admiravelmente plástica, que soube adaptar-se sem perder-se, condescender sem trair-se. Cultura que soube estruturar interligando-os, territórios não contínuos, mas separados por distâncias incomensuráveis; que transplantou traços culturais e realidades materiais da África para a América, da Ásia para a América, sancionando-os e aprovando-os com a sua experiência comum. Assim criou uma unidade para além dos espaços, para além do tempo e até mesmo para além das soberanias. A perenidade desta cultura deverá ser uma obra de sabia e soberana política em comum.

\section{Bibliografia}

CÂMARA, JR. J. MATTOSO. 1979. História e Estrutura da Língua Portuguesa RJ Padrão

COSERIU, E. 1979. Sincronia, diacronia e história: O problema da mudança lingüística [1973], Rio de Janeiro - São Paulo, Presença - USP.

FARACO, Carlos Alberto. 1991. Lingüística Histórica. Ática. São Paulo.

ILLARI, Rodolfo. 1990. Lingüística Românica. Ática. São Paulo.

BASSO, Renato. 2006. O Português da Gente. Contexto. São Paulo.

TEYSSIER, Paul-2001. História da Língua Portuguesa. São Paulo Martins Fontes. 